\title{
Globalization, intellectual property, and economic prosperity ${ }^{\star}$
}

\author{
Michele Boldrin, David K. Levine \\ Dept of Economics, University of Minnesota, Minneapolis, MN, 55455, USA \\ (e-mail mboldrin@econ.umn.edu)
}

\begin{abstract}
Innovation and the adoption of new ideas is fundamental to economic progress, and so is free trade of goods and services. Here we examine the underlying economics of the market for ideas and its implications for trade. From a positive perspective, we examine how such markets function and how international trade interact with them. From a normative perspective, we examine the pitfalls of current intellectual property regulations, and how might they be improved. We highlight recent research by ourselves and others challenging the notion that government awards of monopoly through patents and copyright are "the way" to provide appropriate incentives for innovation.
\end{abstract}

Key words: Economic theory, game theory

JEL Classification: X15, X16

\section{Introduction}

Economic (and, indeed, social) progress is the long run, and altogether surprising, result of the persistent creation of new ideas and goods, their free exchange among individuals, and of the competition among creators, producers and imitators of goods and ideas. As economists have long realized, there would be but a slow and possibly inconsequential improvement in human' s living standard without continuous and sustained innovation. With a constant technology and the same set of goods, the process of capital accumulation alone would, due to the presence of fixed resources and the diminishing returns this brings about, have generated but a fraction

* This article is based on the text of the SER Invited Lecture delivered by Michele Boldrin at the 2003 Simposio de Análisis Económico (Seville). We thank National Science Foundation Grants SES 01-14147 and 03-14713 for financial support.

Corresponding author: Michele Boldrin 
of the growth in per capita income we have witnessed since the inception of human history. Innovation is the engine of change and economic development, hence understanding its nature, internal mechanisms, and the social and institutional factors that bring it about or impede it, is, we believe, the single most important problem faced by the social sciences. It is our contention that understanding innovation is tantamount to understanding competition, as the latter is a necessary condition for the former and the former the spring from which innovations erupt.

While the functioning of competition in the market for goods has been the subject of study for a long time, and our knowledge of the subject appears to have progressed substantially since the times of Adam Smith, it is often felt that the same is not true of the market for ideas. Indeed, there is a widespread view that ideas are dramatically and intrinsically different from goods and that the "economics of knowledge" needs to be grounded on different premises and adopt different modeling strategies than the rest of economics. In this contribution we reconsider this issue and conclude that, while the economic theory of ideas does require modifications in some of the more common assumptions with which markets for regular commodities are handled, such differences are much less dramatic than one would have expected prima facie, and that a great deal of common economic wisdom applies equally well to the economics of knowledge. This allows us to critically reconsider a number of theoretical issues sitting at the intersection between the theory of innovation and technological change and growth and trade theory, to conclude that much "new common wisdom" (otherwise known as "new growth theory" or, in its extreme version, "new economy") is either empirically groundless or logically faulty, and that some old, and possibly uncommon, wisdom, should be brought back to bear on the study of technological change, growth, and trade.

Central to understanding the market for ideas and the incentives for the adoption of new ideas is understanding how ideas might be different from other goods. The starting point of the economic analysis of innovation is to recognize that the economically relevant unit is a copy of an idea. That is, typically, many copies of an idea exist in physical form, such as a book, a computer file or a piece of equipment, or in the form of knowledge embodied in people who know and understand the idea. When embodied in humans, copies of ideas are labeled with a variety of different names, which often obscure their common nature: skills, knowledge, human capital, norms, and so on. Careful inspection shows, though, that each and everyone of these apparently different entities is, at the end, nothing but the embodied copy of an idea, and that the latter was either discovered first by the person in whom it is currently embodied, or costly acquired (possibly via observation and imitation) from other humans, in whom it had been previously and similarly embodied. Economically valuable copies of ideas do not fall from the heavens, like manna, but are the product of intentional and costly human efforts. Only these copies matter, first, in the sense that if they were all to be erased, the idea would no longer have any economic value, and, second, in the sense that the copies are relatively good substitutes for each other: whether a copy of an idea is the original copy or the hundredth copy, it is equally economically useful. From the perspective of the functioning of markets, then, property rights in copies of ideas is assured by the ordinary laws against theft - what is ordinarily referred to as "intellectual property" protects not the ownership 
of copies of ideas, but rather a monopoly over how other people make use of their copies of an idea.

\section{Common fallacies}

Common legal, and often economic, wisdom argues that competitive markets are not suitable for trading copies of ideas, as ideas are intrinsically different from other economic commodities. For the most part these arguments are incorrect. Along most dimensions, ideas are not different form other commodities, and those few dimensions along which ideas are different do not generally affect the functioning of competitive markets. Before moving on to illustrate a positive model of the creation, reproduction and imitation of ideas, we should discuss six mistakes frequently found in the common wisdom about the economics of innovation.

1. It is argued that in competitive markets innovators would be unable to appropriate more than an infinitesimal share of the social value of their ideas. This is a recurrent theme in much business, managerial, and industrial organization literature, where it is apparently believed that economic efficiency requires innovators (or producers more generally, we would believe) to appropriate all the social value of their products. Where this to be the case, any market transaction in which some positive social surplus is realized would be inefficient as producers are "leaving something on the table", to consumers in fact. But, obviously, socially efficient provision of ideas/goods requires, instead, that all ideas/goods with a positive social surplus (i.e. social value larger or at most equal than social cost) be produced. How such surplus is split between producers, consumers, and other entities (suppliers of intermediate inputs, government, etcetera) may, and in general will, affect if all goods with positive social surplus are produced, but there is no general presumption that too few goods will be created unless producers appropriate the whole social surplus. In general, in fact, we would expect producers to bring goods, or ideas, to the market, as long as the private costs of doing so is exceeded by the private gains. Hence, from a social perspective, one should ask: for all ideas with a positive social surplus, is it the case that competitive pricing allows producers to appropriate enough revenues to compensate for their opportunity cost? Strangely enough, this question is seldom asked in the theoretical literature on innovations, and never, to the best of our knowledge, in the empirical one. It misses the fact that ideas combine attributes of both consumption and capital goods. They can be used directly for consumption, such as reading a book, or watching a movie, or they can be used as an input in production, by making copies of a book or movie, or by producing other goods, for example, by using the idea for an improved production process. That the original copy of an idea is the capital good (the tree) from which all other copies (the fruits) must originate enables innovators to appropriate the net present value of all future copies through competitive pricing. Corn seeds, for example, can be eaten or used for producing additional corn, so also combine characteristics of consumption and capital goods. Competitive markets for corn generate the appropriate incentive to invest in corn seed. 
2. The initial copy (or copies, when simultaneous innovation occurs) of an idea are generally produced through a process which is different from the one used to make subsequent copies, as in the case of original research versus teaching. Most capital goods (original research) are used to produce commodities other than themselves - but the fact that capital goods might be used to reproduce themselves poses no particular problem for competitive markets. In the semiconductor industry, for example, reduction in chip size makes it possible to construct capital equipment that can be used to produce even smaller chips.

3. There are suggestions that ideas are subject to "spillover externalities," or what we might call informational leakage. That is, the existence of the idea enables people to learn it and make use of it without the permission of the owners. Some even argue that ideas can be copied for free. In practice, few ideas are subject to informational leakage, and in all cases are costly to reproduce. In the case of copyrightable creations, where the ideas are embodied in physical objects such as books, informational leakage is not an issue. In the case of scientific advances, reflection shows that it is also not the case. While in some sense scientific ideas are widely available, usable copies of scientific ideas are not so easy to come by. Even Newton's laws require a substantial amount of time and effort to understand. For all practical purposes copies are limited to those people who understand the laws and books that explain them. Without paying someone to teach you or buying a book that explains Newton's laws, you are not terribly likely to learn them merely because they are in the public domain. As teachers and professors we earn our living by our ability to communicate ideas to others, and in doing so creating new copies of them. Overwhelming historical evidence shows that diffusion and adoption of innovations is costly and time consuming.

4. It is often argued that leaving ideas in the "public domain" (i.e. without anyone claiming exclusive property of the idea) generates a classical case of the tragedy of the commons, and leads to an inefficient outcome. This is based on faulty economic analysis, and a careful consideration of the issue shows that, in fact, things are exactly the other way around. In some sense, the extent to which ideas resemble other goods can be seen by examining the "public domain" for creative works for which copyright has expired. Although legal scholars have tended to view the public domain as a commons, like the atmosphere or ocean for which there are no property rights, in fact the market for a public domain book is very similar to the market for wheat or any other competitively provided good or service. Once copyright has expired, there are many copies of a book, each a good substitute for the other, and each owned by someone. If you want to read the book, make copies, or turn it into a movie, you must first buy the book from one of the current owners. If there are many owners, each competing with each other to sell you the book, you may be able to obtain it relatively cheaply, even though you intend to turn it into a highly valued movie. But the fact that you can buy ingredients cheaply is a good consequence of competitive markets, not a bad one. In fact, the evidence suggests that the market for goods in the public domain functions well, with copies widely available and reasonably priced: finding a copy of a book by Dickens, for example, is no great problem. 
5. Lawyers have also made other arguments as to why ideas might be different from other goods; but many of these arguments reflect lack of understanding of how markets function. For example, it is often argued that without the monopoly provided by copyright, there would be an inadequate incentive to "promote" works such as books, music and movies, since the benefit of the promotional effort would be shared by competitors. However, this argument applies equally well to other competitive markets, such as that for wheat. The point to understand is that under monopoly, goods are priced high, and the consumer receives little benefit. Hence the monopolist has an incentive to subsidize information to the consumer. In competitive markets, the competitors do not have incentive to subsidize information, so consumers must pay the cost of obtaining it. Information about wheat is widely available - from doctors, diet advisers, books, magazines, and many other sources - but not directly from wheat producers. In competitive markets, not only is information widely available, but it is less biased than the subsidized information provided by monopolists. Markets for ideas are no different in this respect. Plentiful information is available about works in the public domain - but that information is not generally provided by book publishers.

6. Finally, there is one important respect in which ideas are different from other goods: the first copy of an idea must generally be produced as a single indivisible unit. For example, two first halves of a book are not a good substitute for both the first and second half. Although most goods are subject to some degree of indivisibility, quantitatively, the indivisibility is crucial for ideas. The key economic question this raises is whether there is adequate incentive to produce the first copy of an idea. As we will see, ideas will always generate some income for the creator. From an economic perspective, the issue is whether this is enough income to give creators the incentive to invent an adequate number of socially valuable ideas. Making creators fabulously rich is not a relevant issue, unless this is an essential part of the incentive to create. Compensating creators for the opportunity cost creative activity involves is the economic issue to be addressed by the normative theory of innovation.

\section{Innovation with quadratic utility}

In this section we introduce the basic model to be used in the foregoing analysis; we concentrate first on the relationship between the presence of an indivisibility in the innovation technology and the functioning of competitive innovation. It is useful to consider the simplified market for an idea studied by Quah (2002) and Boldrin and Levine (2001). We begin by ignoring the indivisibility so as to understand how the competitive market would lead to efficient provision of ideas, then analyze the impact of indivisibility. We begin by supposing that $x_{0}$ initial copies of an idea can be produced at a per-copy cost of $\mu$. At any moment of time $t$ there are $x_{t}$ copies in existence. As an extreme but innocuous assumption, we imagine that copies of ideas can simultaneously be consumed and reproduced, so that a utility of $u\left(x_{t}\right)$ is obtained by consumers from consuming $x_{t}$ copies of the idea, while 
simultaneously the number of copies available grows at a constant rate, $\dot{x_{t}}=\beta x_{t}$. For simplicity we use the quadratic utility $u\left(x_{t}\right)=2 \rho\left[2\left(x / x^{c}\right)-\left(x / x^{c}\right)^{2}\right]$ for $x \leq x^{c}$ and $u\left(x_{t}\right)=2 \rho$ for $x>x^{c}$. Here $\rho$ is a measure of the "quality" of the idea, a concept we explore below. Observe that the utility maximum $u\left(x_{t}\right)=2 \rho$ is reached at $x_{t}=x^{c}$ which occurs at time $\tau=(1 / \beta) \ln \left(x^{c} / x_{0}\right)$, and that utility remains constant after that date. Overall the present value of consumer utility is $\int_{0}^{\tau} e^{-t} u\left(x_{0} e^{\beta t}\right) d t+\int_{\tau}^{\infty} e^{-t} u\left(x^{c}\right) d t$, where time units have been normalized so that the subjective interest rate is one.

Suppose that the technology for reproducing copies is available to everyone, so that anyone who has a copy can make and sell further copies, in other words: there is no intellectual property. The crucial thing to understand is that because the reproduction technology exhibits constant returns to scale, all of the proceeds from the sale of the idea accrue to the owners of the original copies. For a more general technology, which uses inputs other than copies of the idea itself, the proceeds net of the opportunity cost of those other inputs will also accrue to the owners of the original copies. This is due to competition; that is, there will be many people seeking to profit by making copies of the idea. Think here of a Napster-like distribution system for MP3's, albeit one in which owners of MP3's can legally sell copies. If the amount net of my cost that I could earn by buying MP3's and selling copies was positive then you would compete with me to buy MP3's and sell copies, driving up the price of the existing copies we are each trying to obtain and down that of the copies we are each trying to sell. Ultimately this competition between re-sellers mean that they all earn zero profits. This is not true of the original creators, because, once they produce the initial copies, they own a factor which is in fixed supply; the value of the latter, as we shall see, depends on the speed of reproduction and circumstances of demand.

Competitive provision of copies implies that the price of copies at time $t$ is the marginal social value of an additional copy, $u^{\prime}\left(x_{t}\right)$. Hence, if $\lambda$ is the number of consumers, and the original producer(s) of the idea face competition for creating the first copies of the idea, the profit from producing $x$ initial copies (holding fixed prices $u^{\prime}\left(x_{0} e^{\beta t}\right)$ to reflect competition) is

$$
\lambda \int_{0}^{\tau} e^{-t} u^{\prime}\left(x_{0} e^{\beta t}\right) x e^{\beta t} d t-\mu x
$$

Competitive innovators, then, maximize profits taking prices as given. This is solved by choosing $x$ in such a way that the marginal cost $\mu$ of producing an additional initial copy of the idea equals its marginal social value,

$$
\begin{aligned}
\mu & =\lambda \int_{0}^{\tau} e^{(\beta-1) t} u^{\prime}\left(x_{0} e^{\beta t}\right) d t \equiv P \\
& =\frac{4 \lambda \rho}{x^{c}(\beta-1)}\left[\frac{\beta\left(x_{0} / x^{c}\right)^{(1-\beta) / \beta}+(\beta-1)\left(x_{0} / x^{c}\right)}{2 \beta-1}-1\right] .
\end{aligned}
$$

This is the condition for efficient provision of any good. Note that, in equilibrium, the individually optimal choice of $x$ must equal the aggregate initial capital $x_{0}$. This analysis points out the way in which competitive markets for production 
that takes place over time functions with goods that have both capital and consumption attributes. Here there is no economic problem to be solved that is not already solved by the competitive marketplace.

The problem that arises, as we have indicated, is that of indivisibility. Assume this is such that a choice of $x_{0}<1$ implies no innovation at all. It may be, depending on conditions of demand relative to $\mu$, that the optimal initial choice of capital for a competitive innovator is $x_{0}<1$, so that this indivisibility binds. In this case, the only realistic option is to choose $x_{0}=1$. Although the creator still receives a positive revenue of $P$ it is insufficient to compensate for the cost of creation $\mu$ and so the good is not produced. We should indicate that although it is easy to work out the consequences of a binding indivisibility in this simple setting, general equilibrium theorists have yet to create a comprehensive theory of competitive equilibrium with binding indivisibilities.

In the case of indivisibility, the issue is whether the revenue stream $P$, evaluated at the minimum innovation size $x_{0}=1$, is sufficient to compensate for the cost of creation $\mu$. In the extreme case in which $\beta \rightarrow \infty$ revenue $P \rightarrow 0$; in this case no innovation would take place at all. It is a not uncommon confusion to believe that this limit case is in fact the ordinary case. Both theory and evidence suggest that competition generates substantial revenues for innovators in most practical cases and that binding indivisibilities are the exception, not the rule. Note also a second common source of confusion: the revenue stream $P$ accruing to the innovator almost never corresponds to the full social value of the new idea. This is more so when the invisibility $x_{0} \geq 1$ is binding, and $P$ may be a relatively small fraction of the total additional utility the innovation will bring to society. But this fact is of no concern for economic efficiency, as long as $P \geq \mu$ holds; institutions that allow creators to be compensated for the opportunity cost of their effort yield socially efficient outcomes. Making creators extremely wealthy is a byproduct that is welcome to them, but unnecessary to society.

The creator may have a unique idea, in which case he is a natural monopolist and faces no competition for providing copies of the idea, at least until other entrepreneurs manage to imitate him and build up their own production capacity. Assume this takes a period. Future productive capacity will, in general, depend upon the stock of productive capacity the creator installs in the first period, even if cases in which the ability to imitate is independent of how much the original innovator brings to the market ought to be studied. In keeping with the model used so far, assume that once the natural monopolist sets up the initial capacity, imitators come in at the rate $\beta$ per unit of time. Then, in the initial period he maximizes the objective function $\lambda \int_{0}^{\infty} e^{-t} u^{\prime}\left(x e^{\beta t}\right) x e^{\beta t} d t-\mu x$ with respect to $x$. Notice that here he no longer takes present and future prices $u^{\prime}\left(x e^{\beta t}\right)$ as given, and the solution to this problem is generally to produce too few initial copies of the idea. In this case the creator makes more profit than when there is simultaneous innovation and he is a competitor also in the very first period. However, in the case where the indivisibility binds, the producer is still forced to provide a single initial copy, and this monopoly over the unique idea is irrelevant. 


\section{Results}

First mover advantages: There is plentiful evidence that in practice the indivisibility of ideas is not more substantial than that of other commodities, for example, automobile plants or shipyards. There is also much evidence that ideas flourish in competitive markets without government intervention in the form of patents and copyright. However, for books, music and movies, it is easy to imagine that changes in computer technology that make copying cheaper and more rapid will lead to a $\beta$ so large as to cause $x_{t}$ to expand so rapidly as to flood the market and drive price to zero almost immediately. As we observed, as $\beta \rightarrow \infty$ the revenue $P \rightarrow 0$. It is worth noting that the same technological change is reducing the cost of books, music, and movies creation as well, so that $\mu \rightarrow 0$ also, and this may well offset the improved copying technology. Moreover, even if we accept that the market for copies may be quickly flooded, there are still tremendous advantages in being first. We will not attempt to enumerate those all of those advantages here. In the case of innovations, secrecy is an obvious method of generating a short-term monopoly. In the case of books and movies, most sales take place within three months of initial release. So if it is possible to keep copies encrypted for even so short a period of time, substantial revenues may be realized regardless of the quality of copying technology. Overwhelming empirical evidence from the pharmaceutical industry suggests that the first mover advantage is quite substantial, be it due to reputation effects, slow information diffusion, or simply "capture" of the medical profession. In any case, the evidence shows that most generic drugs, selling at a quarter of the price and being clinically and functionally perfect substitutes for the original products, never capture more than $50 \%$ of the market (Caves et al. 1991; CBO 1998).

The first mover advantage is a form of monopoly accruing to the original innovator. A monopolist, unlike a competitor, will not allow quantity $x_{t}$ to expand to $x^{c}$, which drops the price to zero, but will restrict output to $x^{c} / 2$, which maximizes his revenues. In the limit, as $\beta \rightarrow \infty$ output jumps almost immediately to $x^{c} / 2$, resulting in a revenue to the monopolist of $\lambda \rho$. If this revenue can be captured only for a fraction of time $\phi$, then the corresponding revenue is $\phi \lambda \rho$. For computational simplicity, we will focus hereafter on the case of $\beta$ large, although it considerably understates the benefits of competition. The first mover advantage here may be represented by a fraction $\phi^{F}$ representing time before competitors are able to successfully enter. Patent and copyright monopolies can be represented by a fraction $\phi>\phi^{F}$ representing the duration of the legal protection.

We have seen how under some circumstances there may be underprovision of ideas due to indivisibility. We turn now to the traditional solution to this problem: the government provision of monopoly through patents and copyright. That is, by granting control over how all copies of an idea are used, the government allows the patent or copyright holder to limit reproduction and restrict supply. This increases profits, and so provides greater incentive to create or innovate. There are, however, a number of problems with this solution.

Sequential innovation: Since a monopolist is scarcely likely to earn less than a competitor, it might seem that whatever the problems associated with monopoly, 
government grants of monopoly for innovation at least increase the incentive to innovate. But, just as most commodities are produced by means of other commodities, so are ideas; innovations build on past innovations - so while raising the profit from innovation, granting monopoly on newly created ideas also raises the cost of future new ideas.

We illustrate this with a simple example, collapsing the dynamic model introduced above into a static one in which $\beta=\infty$. Utility continues to be $2 \rho\left[2\left(x / x^{c}\right)-\left(x / x^{c}\right)^{2}\right]$. A monopolist will produce $x^{c} / 2$, resulting in a revenue of $\lambda \rho$. A competitive innovator with a first mover advantage will get a revenue of $\phi^{F} \lambda \rho$. Suppose that to produce the new idea requires the use of $N$ existing ideas. We imagine that each of these many ideas is small, so that the cost of producing a copy of the idea is $\epsilon / N$. Without government monopoly, there will be many copies of each of these existing ideas competing with each other, and the inventor can obtain all $N$ of them for a total cost of $\epsilon$. Without government intervention, this socially desirable invention will take place, provided only that $\phi^{F} \lambda \rho>\epsilon$.

Suppose on the other hand that the government awarded monopoly applies to all innovations, and that the owners of the $N$ existing ideas only know that $\rho$ is drawn from a uniform distribution over $[0, \bar{\rho}]$. Each sets a price $p_{i}$ at which they will license their invention. Then, if owners of all the other existing ideas are setting the price $p$, each owner of an existing idea receives an expected revenue of

$$
\frac{\lambda \bar{\rho}-(N-1) p-p_{i}}{\lambda \bar{\rho}} p_{i}
$$

If $\epsilon<\lambda \bar{\rho} / 2$ the Nash equilibrium of this game is at $p=\lambda \bar{\rho} /(N+1)$, and therefore the inventor must pay $\frac{N}{N+1} \lambda \bar{\rho}$ to clear the needed rights for his own innovation, and so he innovates if he draws an innovation for which

$$
\rho>\frac{N}{N+1} \bar{\rho}
$$

This occurs with probability $1 / N$. By way of contrast without monopoly the probability of innovation is $1-\epsilon /\left(\phi^{F} \lambda \bar{\rho}\right)$. As the number of existing rights that must be cleared increases, the probability of innovation under monopoly is smaller than that under competition, and drops towards zero. Here the additional incentive for innovation under an intellectual property regime is more than completely offset by the additional cost it imposes on innovation. As technologies grow more and more complex, requiring more and more specialized inputs, the monopoly power induced by patents and copyright becomes more and more socially damaging.

Rent-seeking: One of the key problems with government grants of monopoly is the rent-seeking it induces. That is, when governments give away monopolies, there is incentive for would-be monopolists to waste resources competing for the award. In the case of intellectual monopolies, the resources wasted by competing "would be monopolists" takes several forms. The most widely studied is the patent race, where too much effort is invested in innovating quickly in order to be the first to get the patent. Another classical problem is the effort wasted building "work alike" innovations in order to get a portion of the monopoly. This is the case, for example, 
in textbooks, where every textbook is just different enough from the best-seller in the field to avoid violating the copyright. It is also the case in pharmaceuticals, where more time and effort is spent developing copycat drugs to get the share of a lucrative market, than is spent developing genuinely new drugs.

One of the worst aspects of public rent-seeking is the regulatory capture or "monopoly creep" it induces. In the case of regulation, it has been observed that over time the regulatory agency becomes captured by the regulated industry, and far from imposing the public interest on the industry, serves instead to enable collusion and monopolistic practices within the industry. Similarly, in the case of patents and copyrights, over time both the scope and duration of monopoly power has been increased as a consequence of constant rent-seeking. The term of copyright has risen in the USA, for example, from 28 years to 95 years; and many areas of thriving innovation not traditionally subject to patents, such as business practices, are now patentable. So while in a theoretical sense, it might be desirable to have copyrights and patents lasting a few months or a few years, as a practical matter, once copyrights and patents are allowed at all, their term and scope is likely to begin to creep upwards.

The existence of public rent-seeking is not to say that there is not private rentseeking as well. For example, in the absence of patents, innovators are likely to increase their reliance on trade secrecy. Indeed, one argument for patents is that it replaces trade-secrecy, and forces innovators to reveal the secrets of their inventions. Unfortunately, as anyone who has read a patent will realize, the "secret", if there is one, is rarely revealed in a useful way in the patent application. And since patents last 20 years, the only reason to get a patent is if the inventor thinks he cannot keep the secret for that long. We have studied this issue in Boldrin and Levine (2004a), showing that creating public rent-seeking is not a good way to solve the problem of private rent-seeking.

Optimal duration of intellectual monopoly: Although intellectual monopoly may encourage socially desirable innovation, it has a number of drawbacks, as we have seen. These range from the traditional fact that monopolies overprice and undersupply to rent-seeking and the discouragement of subsequent innovation. To understand more clearly the tradeoff involved with government awards of monopoly, we examine a simple example in which we abstract from rent-seeking, sequential innovation and competitive rents. We focus only on the traditional monopoly undersupply, and ask, in a world in which ideas are of variable quality, what is the optimal level of protection $\phi$.

Suppose the first copy of any idea has a unit cost of creation, and the factor used in producing the first copy is abundant and inelastically supplied; reproduction costs are zero. We continue to use $u(x)=2 \rho\left[2\left(x / x^{c}\right)-\left(x / x^{c}\right)^{2}\right]$ for consumer utility. The social value of the idea under monopoly is $(3 / 2) \rho$ and under competition $2 \rho$. Under monopoly revenue equals $\rho$, hence the latter is also a measure of the private value of a good for the monopolistic innovator. We let $\phi$ denote the fraction of the time the producer has a monopoly; without government intervention this is $\phi^{F}$ due to first mover advantage. By providing copyright and/or patent protection, the government can raise $\phi$ to any higher value up to a limit of 1 . There are $\lambda$ 
consumers. Then ideas will be produced for which private revenue exceeds cost, that is $\phi \lambda \rho \geq 1$. In particular, without government intervention, so $\phi=\phi^{F}$, as the size of the economy $\lambda$ grows the quality of the marginal idea that is produced, $\rho=1 / \phi^{F} \lambda$, declines and more ideas are produced. We continue to suppose that ideas are uniformly distributed on $[0, \bar{\rho}]$. We must set $\phi>1 /(\lambda \bar{\rho})$ if any ideas are to be produced at all. Assuming this is the case, social welfare will be

$$
\begin{aligned}
W(\phi, \lambda) & =\int_{1 / \phi \lambda}^{\bar{\rho}}[(2-\phi / 2) \lambda \rho-1] d \rho \\
& =\lambda(1-\phi / 4)\left(\bar{\rho}^{2}-\frac{1}{(\phi \lambda)^{2}}\right)+\frac{1}{\phi \lambda}-\bar{\rho}
\end{aligned}
$$

The derivative of welfare with respect to $\phi$ is

$$
D_{\phi} W=\frac{1}{4 \lambda \phi^{3}}\left(8-\lambda^{2} \bar{\rho}^{2} \phi^{3}-5 \phi\right)
$$

Notice first that the choice of $\phi$ which maximizes social welfare shrinks to $\phi^{F}$ at $\lambda^{F}=\sqrt{(8-5 \phi) /\left(\bar{\rho}^{2}\left(\phi^{F}\right)^{3}\right)}$. Notice second that for $\lambda$ below $\underline{\lambda}=\sqrt{5} / \bar{\rho}<\lambda^{F}$ it is optimal to set $\phi=1$. Notice third that we can characterize the solution by multiplying the welfare derivative by the positive amount $4 \lambda \phi^{3}$. For $\lambda<\lambda \leq \lambda^{F}$, there is a unique $\phi^{*} \geq \phi^{F}$ at which $4 \lambda \phi^{3} D_{\phi} W=0$, and the sign of $D_{\phi}\left[4 \lambda \phi^{3} D_{\phi} W\right]$ is negative at $\phi^{*}$. Finally, as $D_{\lambda}\left[4 \lambda \phi^{3} D_{\phi} W\right]$ is also negative, it follows from the implicit function theorem that $\frac{\partial \phi^{*}}{\partial \lambda}<0$ for $\underline{\lambda}<\lambda \leq \lambda^{F}$. Hence the optimal degree of patent protection is strictly decreasing in the size of the market, strictly so in this range.

In summary, we conclude that if the government is to grant monopolies, they should be limited, as they are by time limits in the case of both patents and copyright. As the market expands through economic growth and trade, these limits should gradually be tightened, until eventually no grants of monopoly are necessary at all. Unfortunately this appears to be the opposite of what has happened.

\section{Conclusion}

Our own conclusion, based on empirical as well as theoretical considerations, is that on balance it would be best to eliminate patents and copyrights altogether. We have seen that markets for ideas are not so different from other markets. At one time government grants of monopoly were widely used as a revenue extraction mechanism, and this is still true in the developing world today. Today we are skeptical about government monopolies. The government monopolies in Eastern Europe not only produced fewer lower quality goods at greater cost, but managed to do greater harm to the environment in the process. In developed economies we have gradually replaced inefficient government grants of monopoly with more efficient mechanisms. Although many economists would not recommend eliminating patents and copyrights altogether, all recognize a strong need for reform. We suggest that insofar as it is desirable for the government to provide extra incentives for invention and 
creation it is not best done through grants of monopoly, but rather through proven mechanisms such as subsidies, prizes or monopoly regulated through mandatory licensing. Just as the world has used the WTO process to gradually harmonize a lower international level of tariffs, increasing greatly the benefits of the free market, so too it should be possible through international collaboration such as TRIPS to harmonize substantial reductions in patent and copyright protection, greatly increasing the benefits of free trade in ideas.

\section{References}

Acemoglu D, Linn J (2004) Market Size in Innovation: Theory and Evidence from the Pharmaceutical Industry. Quarterly Journal of Economics 119: 1049-1090

Boldrin M, Levine D (1999) Perfectly Competitive Innovation. University of Minnesota and UCLA

Boldrin M, Levine DK (2002) The Case Against Intellectual Property. American Economic Review Papers and Proceedings 92: 209-212

Boldrin M, Levine DK (2004a) Rent Seeking and Innovation. Journal of Monetary Economics 51: $127-160$

Boldrin M, Levine DK (2004b) IER Lawrence Klein Lecture: The Case Against Intellectual Monopoly. International Economic Review 45: 327-350

Boldrin M, Levine DK (2004c) Intellectual Property and the Scale of the Market. http://www.econ.umn.edu/ mboldrin

Caves RE, Whinston MD, Hurwitz MA (1991) Patent Expiration, Entry, and Competition in the U.S. Pharmaceutical Industry. Brookings Papers on Economic Activity, Microeconomics: 1-48

Congressional Budget Office (1998) How Increased Competition from Generic Drugs has Affected Prices and Returns in the Pharmaceutical Industry. The Congress of United States, mimeo

Gallini N, Scotchmer S (2001) Intellectual Property: When is it the Best Incentive System? In: Jaffe A, Lerner J, Stern S (eds) Innovation Policy and the Economy, vol 2. MIT Press, Cambridge

Gilbert R, Shapiro C (1990) Optimal Patent Length and Breadth. The RAND Journal of Economics 21: 106-112

Grossman GM, Lai EL (2002) International Protection of Intellectual Property. NBER

Quah D (2002) 24/7 Competitive Innovation. LSE

Scotchmer S (1991) Standing on the Shoulders of Giants: Cumulative Research and the Patent Law. Journal of Economic Perspectives 5: 29-41 